\title{
MECHANISMS OF HIGH TEMPERATURE CREEP OF NICKEL-BASE SUPERALLOYS UNDER LOW APPLIED STRESS
}

\author{
Alexander Epishin ${ }^{1}$ and Thomas Link ${ }^{2}$ \\ ${ }^{1}$ Federal Institute for Materials Research and Testing, Unter den Eichen 87, 12205 Berlin, Germany \\ ${ }^{2}$ Technical University Berlin, Institute for Material Science and Engineering, BH 18, \\ Ernst Reuter Platz 1, 10587 Berlin, Germany
}

Keywords: Superalloys, Creep, Porosity, Dislocations, Diffusion

\begin{abstract}
[001] single-crystal (SC) specimens of the superalloys CMSX-4 and CMSX-10 were tested for creep at $1100^{\circ} \mathrm{C}$ under tensile stresses between 105 and $135 \mathrm{MPa}$. For these testing conditions superalloys show creep curves with the classical shape: primary creep is followed by a long period with low, nearly constant creep rate. It was found that porosity significantly increases during this steady creep. The central point of the investigation was to understand the deformation mechanism of steady creep and its connection with porosity growth. Specimens deformed up to certain strain levels were analyzed by density measurements, scanning electron microscopy (SEM) and transmission electron microscopy (TEM) which supplied information about porosity growth, evolution of the $\gamma / \gamma^{\prime}$ microstructure as well as the mobility and reactions of dislocations during the creep process. It was found that the non-conservative movement (glide/climb) of the $a / 2<011>$ dislocations deposited in the $\gamma / \gamma^{\prime}$ interface during primary creep produces most of the plastic strain during the following steady creep. Interfacial climb creates vacancies, which diffuse either to pores increasing porosity or to interfacial $a<100>$ edge dislocations, assisting their climb through the $\gamma^{\prime}$ phase. Under the testing conditions applied the recovery mechanism is $\gamma^{\prime}$ climb, which has the following two effects: it reduces the constraining of the plastically deformed $\gamma$ phase by the elastically deformed $\gamma^{\prime}$ phase, thus allowing further dislocation glide in the matrix channels and it decreases the osmotic force, which suppresses interfacial glide/climb. Creep deformation accelerates when the $\gamma / \gamma^{\prime}$ microstructure coarsens and the $\gamma^{\prime}$ rafts form junctions, enabling a higher mobility of the $\gamma^{\prime}$ dislocations.
\end{abstract}

\section{Introduction}

Improvement of the efficiency of gas turbine engines requires to increase the gas temperature and consequently the operating temperature of the turbine blades. Rhenium containing SC superalloys like CMSX-4 and CMSX-10 allow a long-term operation of the blade material at temperatures up to about $1100^{\circ} \mathrm{C}[1,2]$. These temperatures are comparatively new and therefore only few investigations on creep mechanisms exist for this temperature range, whereas they are quite frequent for temperatures below $1000^{\circ} \mathrm{C}$ (for an overview see [3]).

In the present work [001] SCs of the superalloys CMSX-4 and CMSX-10 were tested for creep at $1100^{\circ} \mathrm{C}$ and $105-135 \mathrm{MPa}$. For tests at lower temperatures and higher stresses the creep curve has a sigmoidal or exponential shape but in our case superalloys show the classical creep behavior, i.e. pronounced steady creep as observed by several authors [4-6]. During steady creep the material retains the rafted $\gamma / \gamma^{\prime}$ microstructure $[4,7]$ and porosity grows $[8,9]$. Under high stresses, where the $\gamma^{\prime}$ phase can be sheared by couples of $a / 2<011>$ dislocations, the classical mechanism of high temperature $\gamma$ ' cutting [10], rafting reduces the lifetime [11]. But under low stresses, insufficient to press $a / 2<011>$ dislocations into the $\gamma^{\prime}$ superlattice, it improves the creep resistance by retarding the matrix dislocations [4-6]. This is the case in the presented paper. In spite of this retarding effect the plastic deformation continues after primary creep, however the rafted structure deforms with low steady strain rate. The aim of the present investigation was to understand the mechanisms of this steady creep and its connection with porosity growth. This knowledge is intended to use for modeling the creep behavior of superalloys at high temperatures on a microstructural base [12].

\section{Materials and Methods}

The investigated nickel-base single-crystal superalloys of the second and third generation CMSX-4 and CMSX-10 contain about 3 and $6 \mathrm{wt} \%$ rhenium respectively. [001] SC specimens of these superalloys were produced by Doncasters Precision Casting, Bochum, Germany. The specimens were tested for creep at a temperature of $1100^{\circ} \mathrm{C}$ and tensile stresses between 105 and 135 $\mathrm{MPa}$. At first rupture tests were performed to obtain the total creep curves, while further tests were interrupted at characteristic points of the creep curves. The creep induced porosity was determined by density measurement, allowing an accuracy better than $\Delta \rho / \rho=3 \cdot 10^{-4}$ [9].

The coarsening of the $\gamma / \gamma$ ' structure was analyzed by SEM in the secondary dendrite arms representing most of the material. Because the rafted structure is rather regular it allows to apply Fourier analysis for image processing, supplying the structure period $\lambda$, the sum of precipitate and channel width along the stress axis [7]. TEM investigations of specimens from the different creep stages allowed to determine the deformation mechanisms being active during creep.

\section{Results}

At high temperatures and low stresses, superalloys show steady creep, the clearer the lower the stresses. To quantify the duration of steady creep, shown in Figure 1, the relative deviation from the minimum creep rate $\delta \dot{\varepsilon}=100 \% \cdot\left(\dot{\varepsilon}-\dot{\varepsilon}_{\text {min }}\right) / \dot{\varepsilon}_{\text {min }}$ is plotted as a function of time/lifetime $\%$ for CMSX-4 at $1100^{\circ} \mathrm{C}$. Defining "steady creep" as a deformation with $\delta \dot{\varepsilon}$ less than $20 \%$, steady creep lasts under $135 \mathrm{MPa} 1 / 3$ of the lifetime, under $105 \mathrm{MPa} 2 / 3$. 

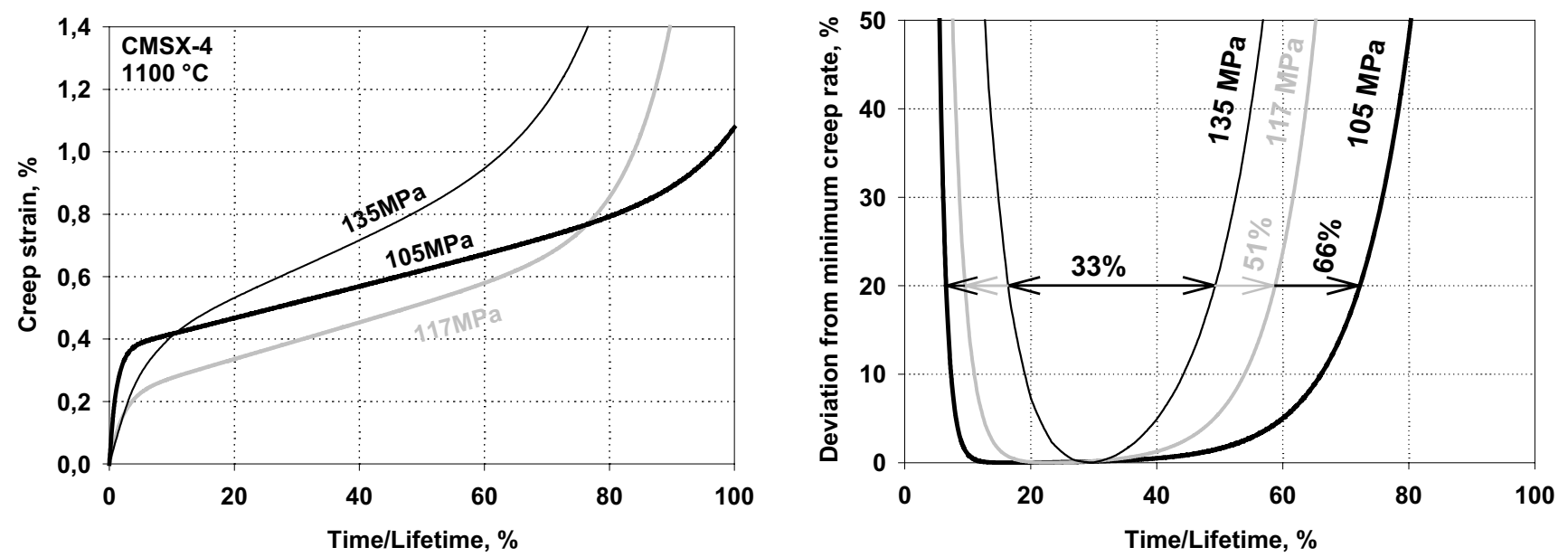

Figure 1 . At $1100^{\circ} \mathrm{C}$ in CMSX-4 primary creep is followed by a region of nearly constant creep rate. This steady creep is the longer the lower the stress. (Lifetimes: For $135 \mathrm{MPa} 149 \mathrm{~h}$, for $117 \mathrm{MPa} 227 \mathrm{~h}$, for $105 \mathrm{MP}$ $692 \mathrm{~h}$. For the $105 \mathrm{MPa}$ specimen rupture necking occurred outside the extensometer.)

Metallographic analysis shows a significant increase in porosity during creep at $1100^{\circ} \mathrm{C}, 120 \mathrm{MPa}$. Visual comparison of Figure $2 \mathrm{a}, 0 \mathrm{~h}$ and Figure $2 \mathrm{~b}, 654 \mathrm{~h}$, gives a qualitative impression of porosity growth in CMSX-10. The pores in Figure 2a, round and positioned in the interdendritic region, are typical for a heat treated, undeformed material.

A detailed inspection of a single pore confirms, that its surfaces is really round (Figure 2c). This becomes remarkable in comparison with crept specimens. Looking there at the pores (Figure. 2b) one still finds big round pores but additionally small

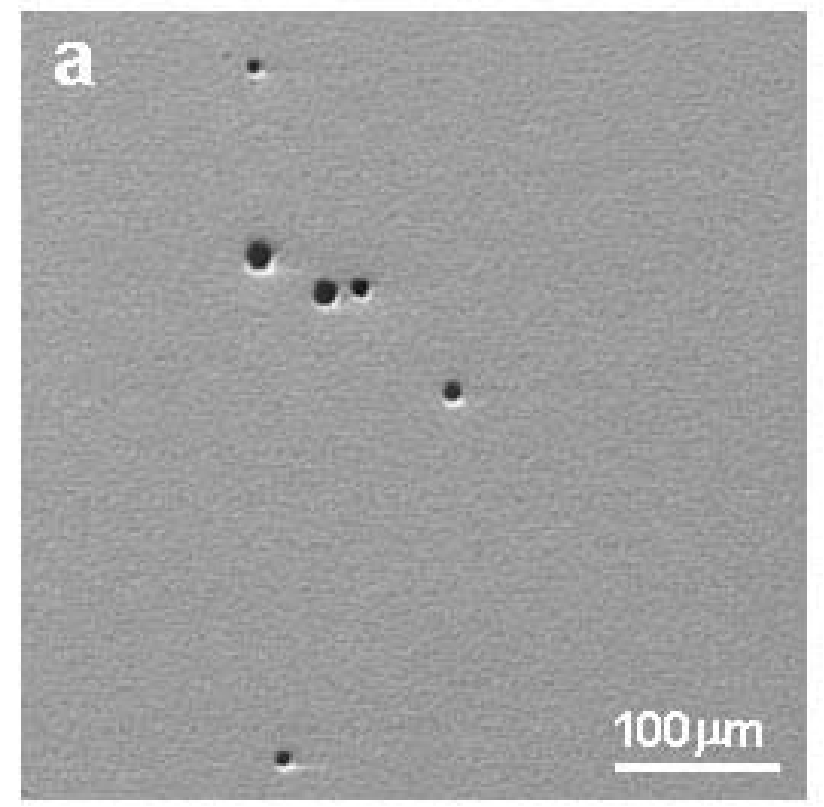

pores, which are now randomly distributed over the whole cross section. Higher magnification reveals their quite perfect crystallographic shape (Figure $2 d$ ) with surfaces of $\{001\}$ type or in other cases $\{011\}$ type. All three features: crystallographic shape, small size and equal distribution are indications for their generation during creep. Searching for the nucleation sites of these creep induced pores one finds in the same specimen at the $\gamma / \gamma^{\prime}$ interface on the $\gamma^{\prime}$ side pores below $1 \mu \mathrm{m}$ size. (Figure $2 \mathrm{e}$ ).

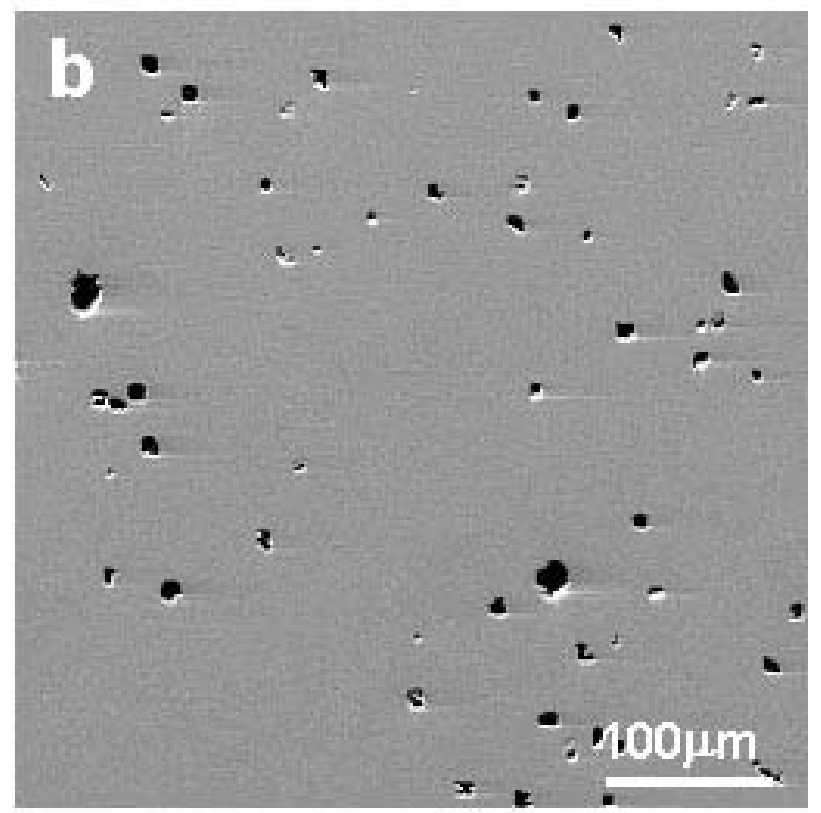

Figure 2. Porosity in CMSX-10, cross-sections, SEM.

Undeformed material after heat treatment, porosity 0.3 area \% (a). Deformed material, $654 \mathrm{~h}, 1100^{\circ} \mathrm{C}, 120 \mathrm{MPa}$, far from the rupture surface, porosity 1.5 area $\%(b)$. 

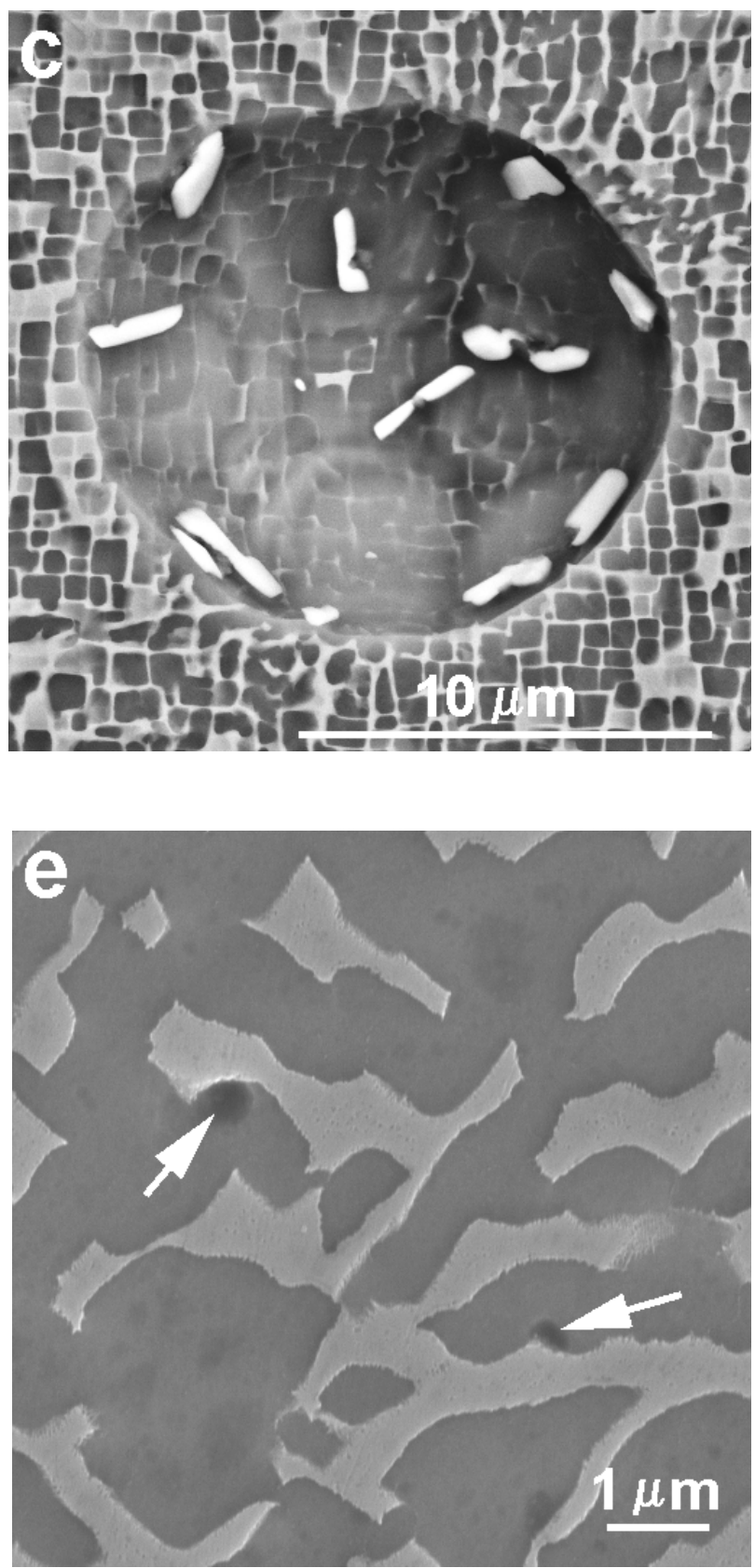

Figure 2. Porosity in CMSX-10, cross-sections, SEM.

Round pore in undeformed material. Diameter about $15 \mu \mathrm{m}$ (c). Pore with crystallographic shape. Same specimen as in figure b. Size about $10 \mu \mathrm{m}$ (d). Pores at the $\gamma / \gamma^{\prime}$ interface (arrows) in the same specimen as in figure b. Size less than $1 \mu \mathrm{m}$ (e).

To analyze the connection between steady creep and porosity growth, first the density at the end of primary creep $\rho\left(t_{p}\right)$ was determined ( $t_{p}=25 \mathrm{~h}$ for CMSX-4 and $60 \mathrm{~h}$ for CMSX-10). Then the relative decrease of the density $\Delta \rho / \rho$ was measured, which is equal to the deformation induced porosity $V_{D}$ having developed during further creep: $V_{D}=-\Delta \rho / \rho$. The steady creep strain $\varepsilon_{s t}$ was calculated as the additional strain after primary creep using the minimum creep rate $\dot{\varepsilon}_{\min }: \varepsilon_{s t}=\dot{\varepsilon}_{\min }\left(t-t_{p}\right)$. This linear
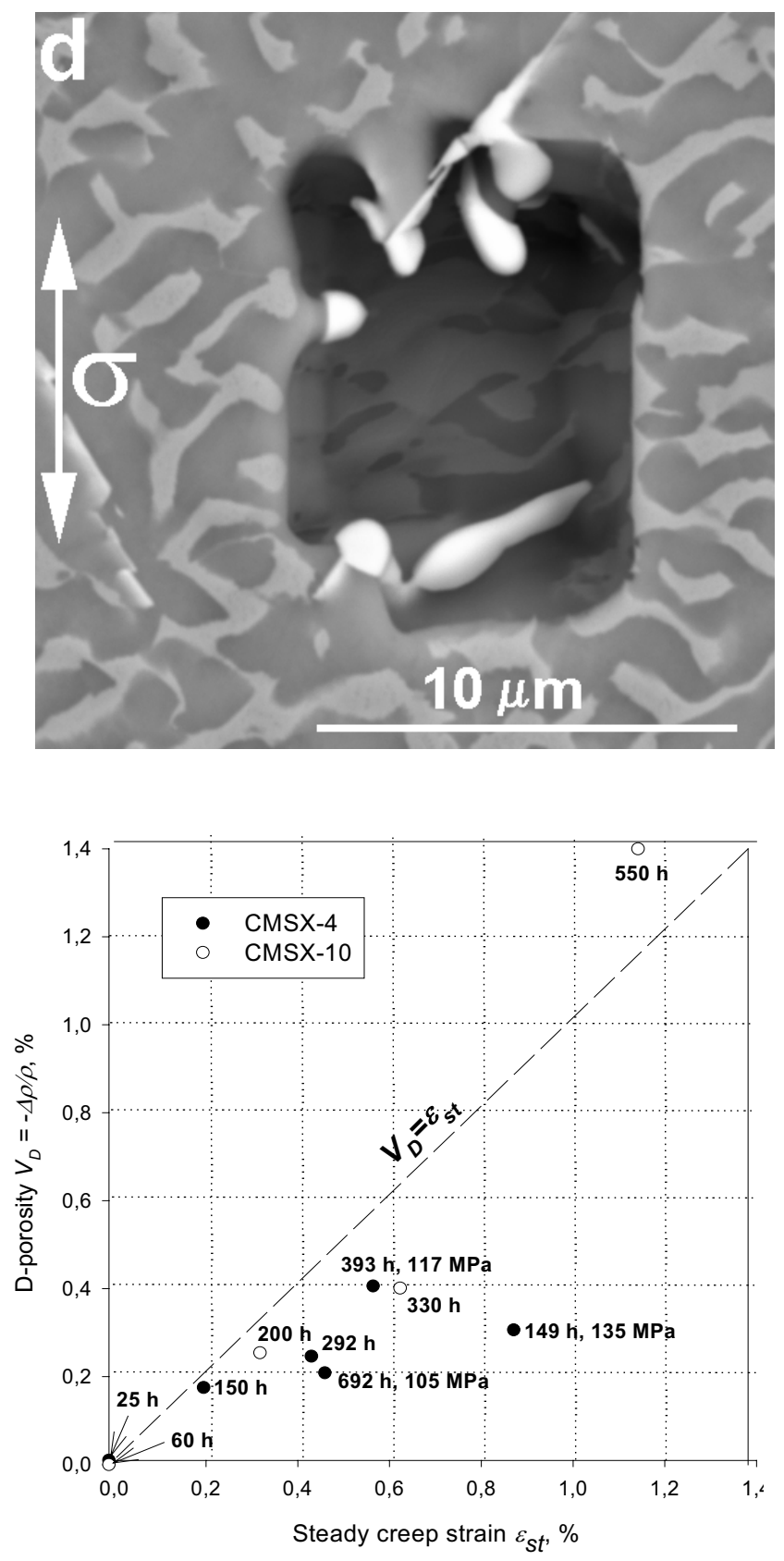

Figure3. Steady creep strain at $1100^{\circ} \mathrm{C}$ is connected with the increase of porosity. Black dots: CMSX-4, white dots: CMSX10. The dots without given stress level correspond to $120 \mathrm{MPa}$

increase $\varepsilon_{s t}$ was compared with the growth of porosity.

Figure 3 shows the results obtained for CMSX- 4 and CMSX-10. If the creep mechanism, leading to the growth of porosity, is the only mechanism, which is active during steady creep, the experimental points should lie on the dashed line. Indeed the measuring points come close to this line. The strongest deviation was found for the specimen with the highest stress of $135 \mathrm{MPa}$, indicating that at higher stresses different creep mechanisms are activated, which are dominant for the strain. 
Fig. 4 shows the coarsening kinetics of the $\gamma / \gamma^{\prime}$ microstructure during creep at $1100^{\circ} \mathrm{C}$, for CMSX-4 at $117 \mathrm{MPa}$ and for CMSX-10 at $120 \mathrm{MPa}$. The points marked as "Rafted" correspond to specimens where complete $\gamma$ ' rafting perpendicular to the load axis first was found. The horizontal arrows mark the steady creep interval $t_{s t}$ determined by the $\delta \dot{\varepsilon}<$ $20 \%$ criterion. The graph shows that the beginning of steady creep coincides with the end of rafting, which is in agreement with [4-6], where rafting is reported to have a strengthening effect in case of low applied stresses.

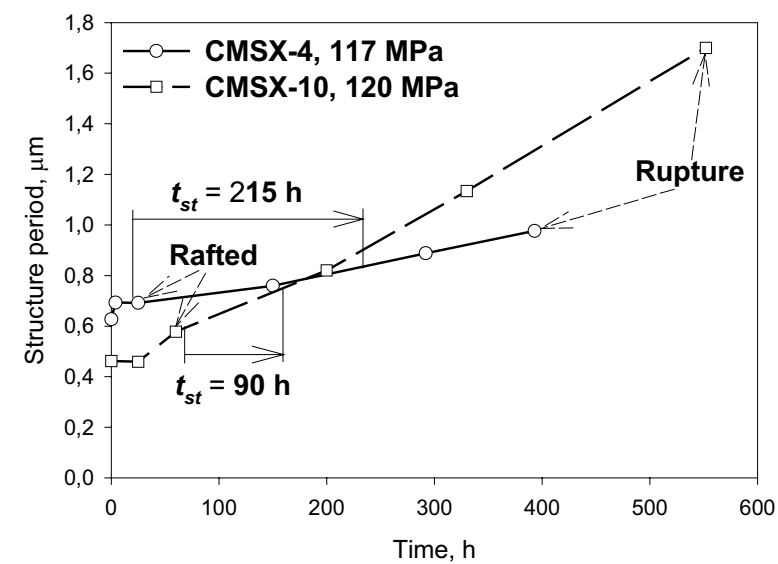

Figure 4. Coarsening of the $\gamma / \gamma^{\prime}$ microstructure during creep at $1100^{\circ} \mathrm{C}$, measured in the secondary dendrite arm

It follows from the graph that creep accelerates when the rafted $\gamma / \gamma^{\prime}$ microstructure coarsens up to $\Delta \lambda / \lambda=15-25 \%$. This increase in size is accompanied by a morphology change called "topological inversion" [13]: $\gamma$ is now embedded in $\gamma$ '. It should be mentioned that the coarsening rate $d \lambda / d t$ in CMSX-10 is nearly three times higher than in CMSX-4 $\left(d \lambda / d t=23 \cdot 10^{-4} \mu \mathrm{m} / \mathrm{h}\right.$ and $\left.8 \cdot 10^{-4} \mu \mathrm{m} / \mathrm{h}\right)$, which causes a similar reduction of $t_{s t}(90 \mathrm{~h}$ versus $215 \mathrm{~h}$ ). The reason for the faster coarsening of CMSX-10 is probably the smaller aspect ratio of the rafts (raft length/raft thickness). This could be caused by the less regular alignment of the $\gamma^{\prime}$ cuboids in undeformed CMSX-10 due to the lower absolute value of the $\gamma / \gamma^{\prime}$-misfit.

TEM analysis of interfacial dislocations in CMSX-4 and CMSX-10 specimens confirmed earlier findings [13], that deformation starts with the expansion of $a / 2<101>$ dislocations gliding through the matrix channels and leaving behind $60^{\circ}$ dislocations in the interfaces. (A bold index means, that its position is fixed. The stress direction is [001]) Plastic deformation produced by this glide takes place only in the matrix. The $\gamma^{\prime}$ phase adapts to the strain elastically and becomes thus the source for induced back stresses: the harder $\gamma^{\prime}$ phase constrains the softer $\gamma$ phase. The interfacial dislocations move along the (001) interface and form regular networks, a process accompanied with the formation of $a / 2<110>$ segments, i.e. with Burgers vectors lying in the interface. The interfacial movement is a glide/climb process producing plastic strain which under tensile stress contributes to the specimen elongation. Because interfacial climb absorbs atoms for the growth of the half extraplanes, it simultaneously generates vacancies at the interfaces which condense either in existing pores or conglomerate into new pores. Thus the growth of porosity during creep is an indication of active interfacial movement. The increasing vacancy concentration results in an osmotic force suppressing the movement of the interfacial dislocations. So both, the back stress and the osmotic force are hindering further deformation.
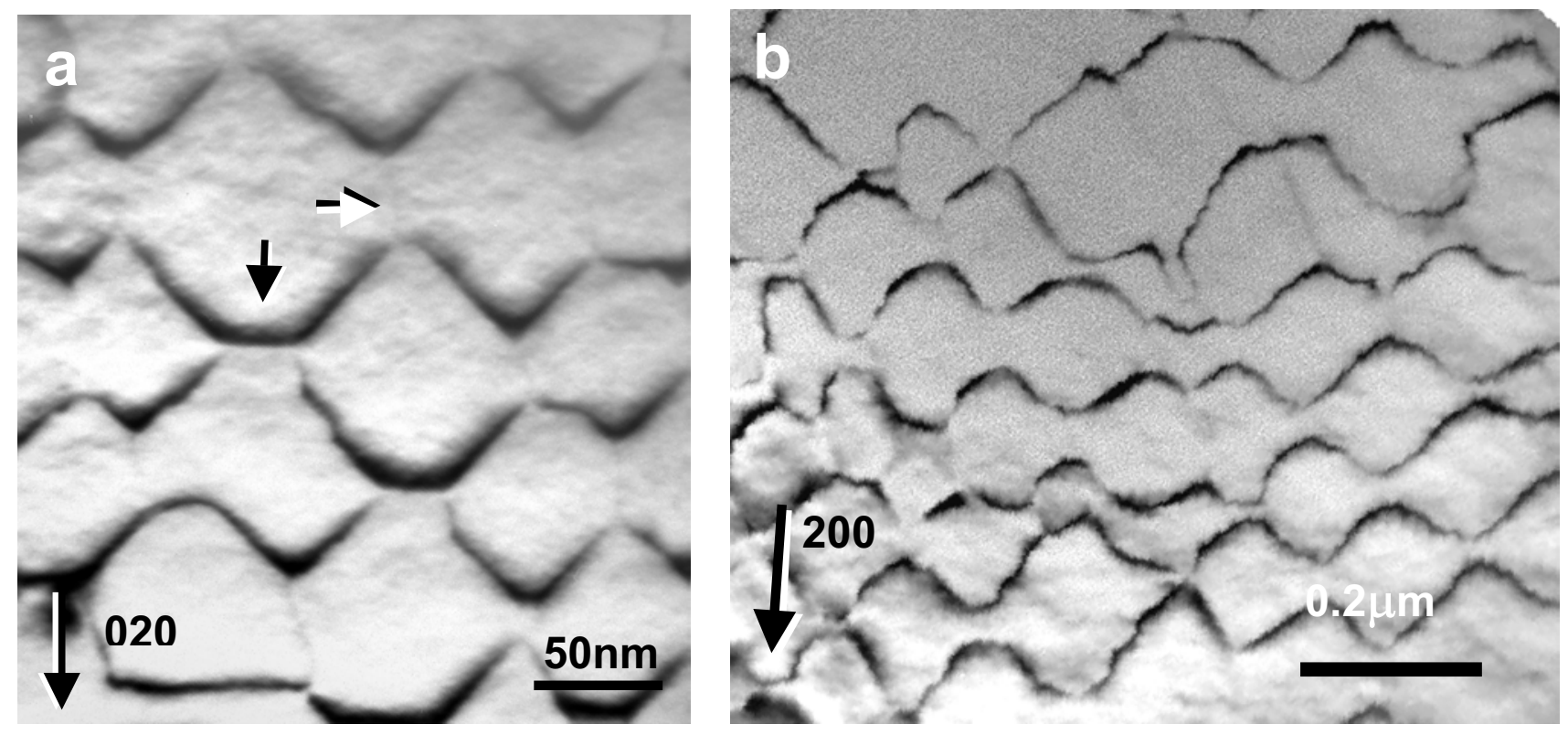

Figure 5. Interfacial dislocations in CMSX-10 after $200 \mathrm{~h}$ creep at $1100^{\circ} \mathrm{C}, 120 \mathrm{MPa}$, transition from steady to accelerated creep. Dislocation reactions lead to segments with $a<100>$ Burgers vectors. Horizontal segment (black arrow): $a[010]$, vertical (white arrow, dislocation out of contrast): $a[100]$. Incident beam direction: [001] (a). Network segments are bowed out in several parts of the network (b). 
Analysis of interfacial dislocation networks in the $200 \mathrm{~h}$ specimen gave that reactions between $a / 2<110>$ dislocations now lead to segments with $a<100>$ Burgers vectors (Figure 5a). Figure 5b shows, how the network looks in CMSX-10 after 200 $\mathrm{h}$ creep at $1100^{\circ} \mathrm{C}, 120 \mathrm{MPa}$. The meshes of the networks have bowed out, indicating a shift of the network in the interface possibly due to reduction of the osmotic force.

Further investigations revealed, that the $a<100>$ interfacial dislocations are the source for a recovery mechanism, which allows creep to continue. Figure 6 a shows a section through a $\gamma$ ' raft in CMSX-4 in the middle of steady creep. The $\gamma / \gamma$, interfaces are densely covered with dislocations, some of which are entering the $\gamma^{\prime}$ phase, forming little loops. Further expansion of these prismatic loops is shown in Figure 6b. Obviously the loops are moving from the lower to the upper interface. Detailed analysis [14] gave that the line vectors of the dislocations are lying in the $\{010\}$ planes while the Burgers vectors are $a<100>$. Thus the image shows $a[010]$ edge dislocations, penetrating the $\gamma$ ' raft by climb. The climb itself does not cause a specimen elongation, but it annihilates interfacial dislocations, thus reducing the back stress and absorbing vacancies, which reduces the osmotic force. This allows further dislocation movement both in the matrix and the interfaces, i.e. $a<100>$ climb indirectly contributes to the specimen elongation.
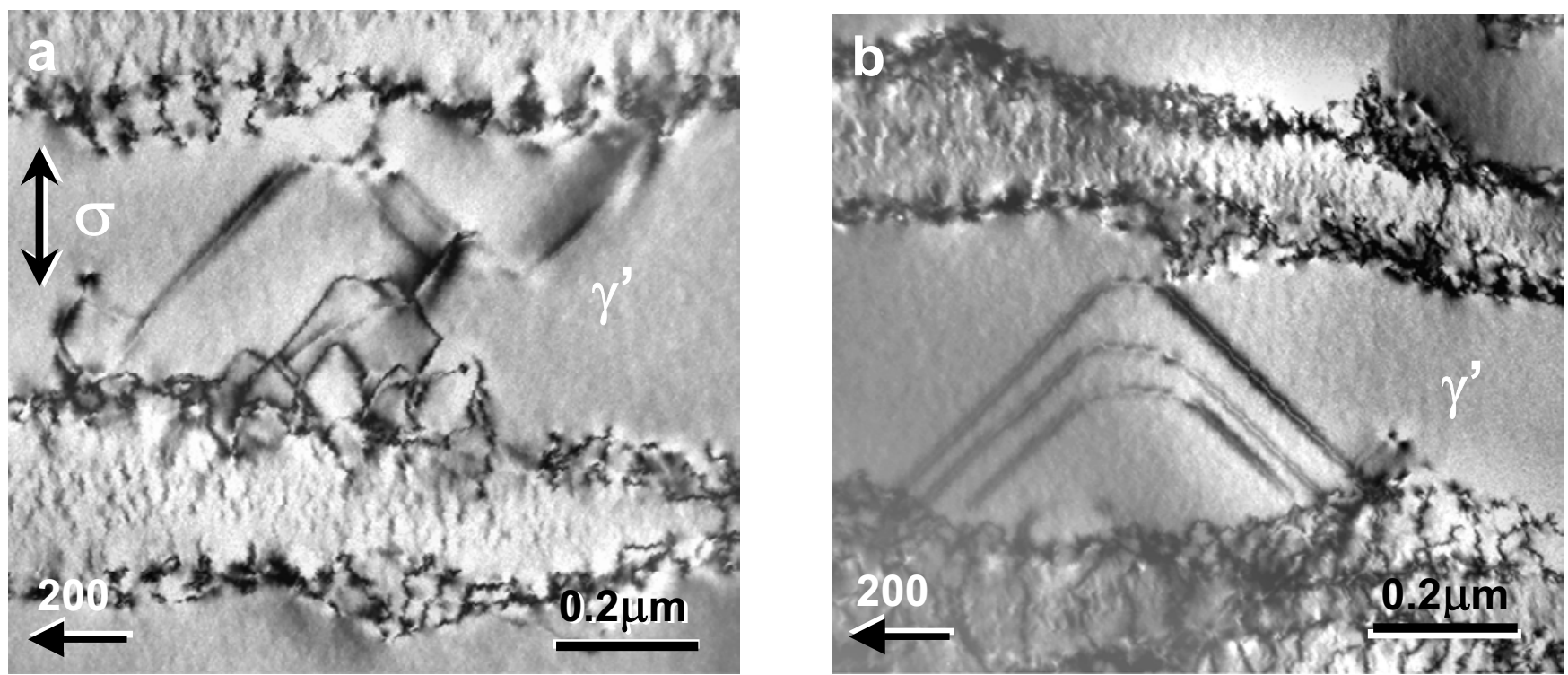

Figure 6. Longitudinal section through the rafted structure of CMSX-4 after $150 \mathrm{~h}$ creep at $1100^{\circ} \mathrm{C}, 120 \mathrm{MPa}$. Interfacial dislocations are entering the $\gamma^{\prime}$ phase (a). $a[010]$ edge dislocations are penetrating the $\gamma^{\prime}$ phase by climb (b). The double line is a contrast effect of a single dislocation line, not of a dislocation pair. Incident beam direction [010].
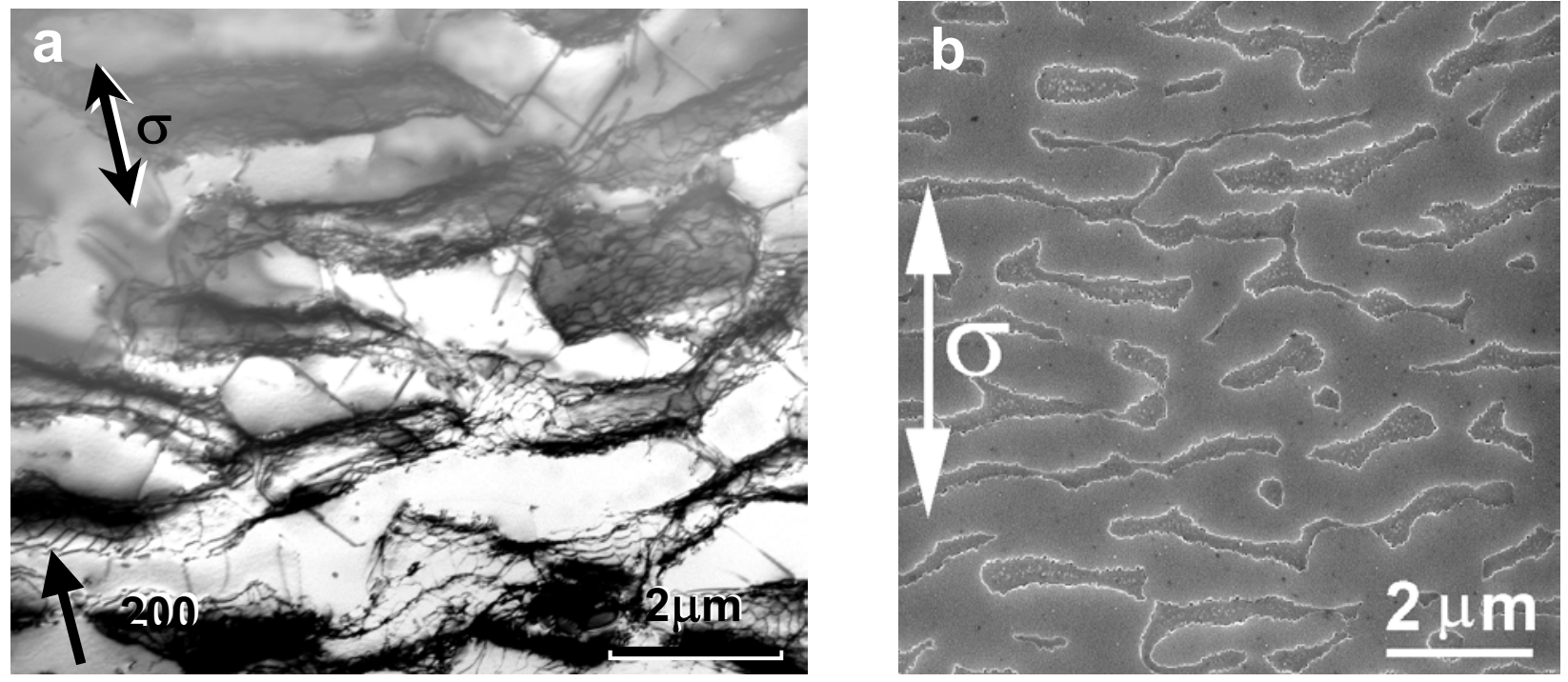

Figure 7. Longitudinal section through CMSX-10 after $200 \mathrm{~h}$ creep at $1100^{\circ} \mathrm{C}, 120 \mathrm{MPa}$. TEM image, showing prismatic loops in the rafts (a). SEM image, showing connections between the rafts (b). 
A TEM overview in CMSX-10 after $200 \mathrm{~h}$ creep at $1100^{\circ} \mathrm{C}, 120$ MPa shows, that such prismatic loops are frequent during the transition from steady to accelerated creep (Figure 7a). A SEM image of the same specimen (Figure 7b) shows that the rafts are now connected while the matrix channels are interrupted, which can be quantified in terms of topological inversion [13, 15]. The $\gamma$ ' phase, now playing the role of the matrix, provides channels for the expansion of the $\gamma^{\prime}$ dislocations throughout the material. Therefore the strain rate increases and the creep process enters into the accelerated stage.

\section{Discussion}

The main question in this investigation of the creep of superalloys at high temperature and low stresses is: how does creep continue when rafts have formed and the dislocation movement in the matrix channels is blocked by back stresses? Usual answers are: the rafts have to be cut or the dislocations have to climb around. But when the stresses are too low for $\gamma$ ' cutting and the $\gamma^{\prime}$ cubes have fused into extended plates, both explanations fail.

The experimental fact, that steady creep strain and porosity increase are connected is an indication for a new mechanism. The central point for the explanation of porosity is, that dislocation movement (glide/climb) in the rafted $\gamma / \gamma^{\prime}$ microstructure is possible in the $\gamma / \gamma^{\prime}$ interfaces, i.e. perpendicular to the stress axis. The specimen length increases because the half extraplanes inserted perpendicular to the stress direction grow. The result of the climb component of this movement are the vacancies, which manifests by the porosity growth observed. The next experimental observation are the interfacial $a<100>$ dislocations, entering and penetrating the $\gamma$ ' phase under osmotic and misfit forces. These dislocations are additionally acting as vacancy sinks, because their extraplanes are shrinking. Figure 8 shows the connection between interfacial glide/climb, porosity growth and $\gamma^{\prime}$ climb. It should be mentioned that the $\gamma^{\prime}$ climb observed differs from a complex $\gamma$ ' movement of $a<100>$ dislocations under shear creep loading observed in [16]. The movement there was interpreted as $\gamma$ ' cutting, i.e. as a combination of zigzag displacements resulting in a macroscopic movement along $\{110\}$ or $\{111\}$ glide planes. The classical mechanism of $\gamma^{\prime}$ deformation during the accelerated stage of high temperature creep is shearing by pairs of $a / 2<101>$ dislocation [10]. So this is certainly the first idea for interpreting Figure 6. The correct solution however follows from the TEM analysis of Burgers and line vectors: the dislocations are $a<100>$ prismatic loops climbing through the $\gamma$ ' phase.

A consequence of the relaxation mechanism described above is, that glide of $a / 2<101>$ dislocation loops in the matrix channels, blocked before by back stresses becomes possible again. The question is: how much of the stationary creep strain is based on interfacial glide/climb and how much on this additional matrix loops? The ratio $R$ between these two strain contributions can be quantified using the experimental value ([001] creep strain)/(increase in pore volume fraction) as described in detail in [17]. This consideration allows to estimate, that in CMSX-4 and CMSX-10 at $1100^{\circ} \mathrm{C}$ and stresses of $105-120 \mathrm{MPa}$ about $85 \%$ of the secondary creep strain are caused by interfacial dislocation movement.

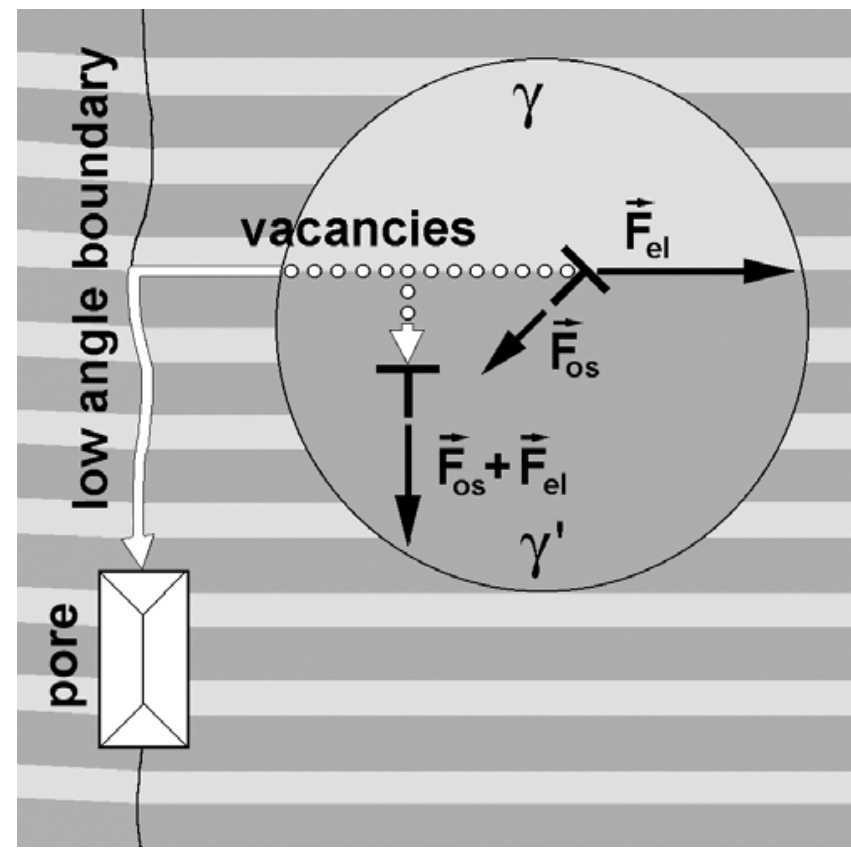

Figure 8. Connection between dislocation movement, vacancies and pores. The interfacial glide/climb, shown by a tilted dislocation in the $\gamma / \gamma$ ' interface, produces vacancies (white circles). They diffuse along the interface and low angle boundaries and condense in pores or they support the climb of $a<100>$ dislocations through the $\gamma$ '-phase. (big circle: enlarged $\gamma / \gamma^{\prime}$ interface)

\section{Conclusions}

At high temperatures and low stresses primary creep of superalloys is followed by a long creep period with low, nearly constant strain rate. The deformation mechanism being active in the completely rafted $\gamma / \gamma^{\prime}$ structure is mainly transverse climb/glide of $a / 2<101>$ interfacial dislocations.

Macroscopically this climb results in a specimen elongation, microscopically in the generation of vacancies and dislocation segments with $a<100>$ Burgers vectors. The vacancies either condense forming pores or allow the interfacial $a<100>$ segments to climb as prismatic loops through the rafts.

Vacancy annihilation and climb through the rafts are both relaxation mechanisms, allowing additional $a / 2<101>$ glide in the matrix channels.

Creep accelerates when the $\gamma / \gamma^{\prime}$ structure topologically inverts, giving way for $a<100>$ dislocations to spread over the simply connected $\gamma^{\prime}$ phase.

\section{Acknowledgement}

The authors wish to thank the Deutsche Forschungsgemeinschaft for financial support (Project PO 405/7-1, RE 688/41-1).

\section{References}

1. D.J. Frazier, J.R. Whetstone, K. Harris, G.L. Erickson, R.E. Schwer, „Process and Alloy Optimization for CMSX-4 Superalloy Single crystal Airfoils”, in: E. Bachelet et al. (Eds.), High Temperature Materials for Power Engineering 1990, D. Reichel, Dordrecht, (1990), 1281-1300. 
2. G.L. Erikson, "The Development and Application of CMSX-10," Superalloys 1996, Edited by R.Kissinger, D.J. Deye, SD.L. Anton, A.D. Cetel, M.V. Nathal, T.M. Pollock and D.A. Woodford, TMS, (1996), 35-44.

3. T.M. Pollock and R.D. Field, "Dislocations and High Temperature Plastic Deformation of Superalloy Single Crystals," Dislocations in Solids, Vol. 11., F. R. N. Nabarro and M.S. Duesbery, editors, Elsevier, Amsterdam, (2002).

4. R.A. MacKay and L. J Ebert, "Development of $\gamma-\gamma$ ' Lamellar Structures in a Nickel-Base Superalloy during Elevated Temperature Mechanical Testing," Metall. Trans. A, 16A (1985), 1969-1982.

5. W. Schneider, "High Temperature Creep Behavior and Microstructure of the Single Crystal Superalloy CMSX-4 at Temperatures from $800^{\circ} \mathrm{C}$ up to $1100^{\circ} \mathrm{C}$," ( $\mathrm{PhD}$ thesis, Erlangen-Nürnberg University, Germany, 1993), 65-69.

6. R.C. Reed, N. Matan, D.C. Cox, M.A. Rist and C.M.F Rae,"Creep of CMSX-4 Superalloy Single Crystals: Effect of Rafting at high Temperature," Acta mater., 47, (1999), 33673381 .

7. A. Epishin et al. "Evolution of the $\gamma / \gamma$ ' microstructure during high temperature creep of a nickel base superalloy," Acta mater., 48, (2000) 4169-4177

8. J. Komenda and P.J. Henderson, "Growth of pores during the creep of a single crystal nickel-base superalloy," Scripta mater. 37 (1997), 1821-1826.

9. A. Epishin et al., "Investigation of Porosity in SingleCrystal Nickel-Base Superalloys," Proceedings of the 7th Conference on Materials for Advanced Power Engineering, Liege, 2002), 217-226

10. B.H. Kear and J.M. Oblak, "Deformation Modes in $\gamma$ ' Precipitation Hardened Nickel-Base Alloys," Journal de Physique, (1974), C7-35-45

11. H. Mughrabi ' $\gamma / \gamma$ ' Rafting and its Effect on the Creep and Fatigue Behaviour of Monocrystalline Superalloys", The Johannes Weertman Symposium, ed. R.J. Arsenault et al.: (The Minerals, Metals \& Materials Society, 1996), 267-278.

12. B. Fedelich, "A microstructure based constitutive model for the mechanical behavior at high temperature of nickel-base single crystal superalloys" Computational. Materials Science, 16, (1999), 248-258.

13. A. Fredholm and J.L. Strudel, "High-Temperature Creep Mechanisms in Single Crystals of some High Performance Nickel-Base Superalloys" (High Temperature Alloys, Their Expoitable Potential, Proc. of Petten. Int. Conf. 1985, ed. J.B. Mariott et al., Elsevier Applied Science, London, 1987), $9-18$

14. M. Klaus, "Development of the dislocation Structure in CMSX-10 during High Temperature Creep" (Diploma thesis, Technical University Berlin, Germany, 2003), 44-50
15. A. Epishin et al., "Kinetics of the topological Inversion of the $\gamma / \gamma$ ' Microstructure during Creep of a Nickelbased Superalloy," Acta mater. 49 (2001), 4017-4023

16. G. Eggeler and A. Dlouhy, "On the Formation of $<010>$-Dislocations in the $\gamma$ '-Phase of Superalloy Single Crystals During High Temperature Low Stress creep," Acta mater., 45, 10, (1997), 4251-4262.

17. A. Epishin and T. Link, "Mechanisms of High Temperature Creep of Nickel-Base Superalloys under Low Applied Stresses," Phil. Mag. Acc. for publ. (2004) 
